\title{
SHH Positive
}

National Cancer Institute

\section{Source}

National Cancer Institute. SHH Positive. NCI Thesaurus. Code C157582.

An indication that $\mathrm{SHH}$ expression has been detected in a sample. 